\title{
Елена Коряковцева
}

Естественно-гуманитарный университет (Седльцее, Польша)

\section{ОККАЗИОНАЛИЗМЫ В РЕКЛАМНЫХ ТЕКСТАХ: К ВОПРОСУ О КОГНИТИВНОМ КОДИРОВАНИИ (НА МАТЕРИАЛЕ РУССКОГО И ПОЛЬСКОГО ЯЗЫКОВ)}

Как известно, рекламный текст - это сложное семиотическое целое, представляющее собой свободную - как линейную, так и нелинейную - последовательность знаковых единиц, максимально приспособленную для выполнения главной задачи - продвижения на рынок рекламируемого продукта (Котлер 1996: 24). В рекламном тексте языковое манипулирование играет роль механизма социального приспособительного «общения», в ходе которого с учетом специфики реакций на тот или иной стимул подбираются наиболее эффективные коммуникативные стратегии, позволяющие точно и гибко подстроиться под целевую группу потребителей (Benedikt 2004: 114-115; Пашутин 2007). Манипулируя их сознанием, копирайтеры используют разнообразные приёмы эмоционализации высказываний, добиваясь в кратких рекламных текстах максимальной концентрации экспрессивов, в том числе - словообразовательных.

Среди неодериватов-экспрессивов, в значениях которых сочетаются эмоционально-аффективные и логико-понятийные компоненты, особое место занимают окказионализмы - нестандартные, нередко экстравагантные, но в то же время вполне понятные потребителям из определенных целевых групп. Эффективное когнитивное кодирование потребителей осуществляется путём их вовлечения в процесс дешифровки окказиональных экспрессивов с помощью внешнего контекста или пресуппозиции, т.е. на базе знаний реципиентов рекламы. Следует заметить, что адекватному восприятию рекламного текста, как правило - креолизованного, способствуют также рекламные образы, которые транслируют тот же смысл, что и экспрессивные окказионализмы. Объектом анализа в данной статье являются структура, семантика и прагмастилистические свойства русских и польских окказионализмов-экспрессивов, в том числе - хрематонимов, при сопоставлении которых нами было выявлено сходство механизмов рекламистского словотворчества. 
Являясь ярким средством выразительности, привлекающим внимание к предмету рекламы, окказионализм-экспрессив обладает большой силой воздействия благодаря как своей структурной нестандартности, так и наслоению смысловых оттенков. Это наслоение смысловых оттенков, иными словами - семантическая компрессия, обуславливается: а) многозначностью мотивирующего слова; б) многозначностью форманта; в) свертыванием структуры исходной синтаксической конструкции и концентрацией ее смысла в деривате. Семантическая компрессия при образовании рекламных окказионализмов, как правило, сопровождается компрессией формальной, т.е. сокращением формы производящего слова либо трансформацией мотивирующего усеченного словосочетания (мультивербизма) в синтетическое однословное наименование. Рекламные тексты, основная задача которых - дать как можно больше сведений в пределах сжатой лексико-синтаксической структуры, являются благоприятной средой для образования деривационных формально-семантических компрессатов, которые не только обозначают феномены, нуждающиеся в комплексной номинации, но и передают оценочную информацию в максимально сконденсированной форме.

Уникальная морфемная структура и сложная семантика рекламных окказионализмов во многом затрудняют их типизацию. Однако в соответствии с законом аналогии, лежащим в основе порождения всех видов неолексем, способ образования окказионализмов, как правило, подсказывается аналогическим фоном, в качестве которого выступает однокоренное и/или одноструктурное слово, нередко включаемое в тот же внешний контекст, что и окказионализм.

Анализ лексического состава около 2000 русских и польских рекламных слоганов, содержащихся в специальных интернет-базах и словарях показал, что при создании окказионализмов их творцы-копирайтеры чаще всего осуществляют одну из пяти словопроизводственных операций ${ }^{1}$, результаты которых и будут ниже проанализированы.

1. Используются, хотя и редко, непродуктивные словообразовательные типы и модели. Так, внимание потребителей к рекламе фильтров для воды «Барьер» - наш поилец привлекает архаичный народно-поэтический интенсификатор поилец «тот, кто поит и содержит всю семью», созданный по модели, непродуктивной в современном русском языке, и потому воспринимаемый как окказионализм, образованный по аналогии с отглагольным именем деятеля кормилеи. Обычно же лексемы, созданные в современном

\footnotetext{
${ }^{1}$ Следует заметить, что рассматривая приёмы сознательного речевого новаторства, мы принимали во внимание тот факт, что сопоставляемые русские и польские окказиональные неодериваты являются индивидуально-авторскими словами и в то же время отражают потенции сопоставляемых языков, а значит, далеко не всегда могут быть переведены с сохранением модели окказионализма, извлеченного из текста оригинала.
} 
русском языке по непродуктивным моделям, малопонятны и потому должны быть вписаны в поясняющий внешний контекст, как, например, рекламный окказионализм Хрустец - название сухариков, производимых компанией «Уником».

Неодериват Хрустец, образованный по непродуктивной модели отглагольных существительных с суффиксом -ец-, имеет синкретичное значение, поэтому может быть воспринят и как название деятеля ('тот, кто хрустит', ср.: жнец, творец), и как название объекта-инструмента действия ('то, чем хрустят', ср. резец). Многозначность окказионализма хрустец, обусловленная многозначностью суффикса -ец, поддерживается рекламным слоганом Сухарики Хрустец. Рекорд вкуса. Субъектное значение окказионализма (хрустец - 'тот, кто хрустит сухариками') актуализируется с помощью визуального кода, т.е. изображения зубастого супермена на упаковке сухариков, который, по-видимому, может поставить рекорд в их поедании.

Польские копирайтеры также создают окказионализмы по непродуктивным моделям, помещая эти «одноразовые единицы», ограниченные функционально и семантически, во внешний контекст, который содержит узуальное одноструктурное слово с тем же эмпирически непродуктивным формантом, ср.: Winiary. Rosół drobiowy. Zostań bulionerem и Zostań milionerem dzięki loterii w naszych bulionach Winiary (создатель окказионализма - копирайтер Ярослав Коч, см. https://www.behance.net/JarekKoc).

2. При создании окказионализмов нарушаются ограничения, которые накладывает языковая система на тот или иной словообразовательный тип. Чаще всего это нарушение лексико-грамматической, стилистической и семантической сочетаемости. Такие несистемные экспрессивные окказионализмы, появляющиеся обычно в слоганах и рекламных зачинах, как правило, образуются от производящих основ иных лексико-грамматических свойств, чем требуется по условиям словообразовательного типа. Пример тому - наречие пятизвёздно, образованное российским копирайтером с нарушением лексико-грамматической сочетаемости суффикса -о- (Не просто чисто, а пятизвёздно чисто. Ariel 5 звезд). Наречие степени качества создано на базе относительного прилагательного пятизвёздныц̆, которое может быть употреблено в метафорическом значении, базирующемся на импликационных признаках мотивирующего словосочетания пять звёзд - словесного аналога значка, символизирующего наивысшее качество. Ср. с польским окказиональным наречием-экспрессивом honernie («Honer), где производящим словом является имя собственное - название фирмы Honer, ср.: Honernie dobre $i$ tanie okna i drzwi! (реклама изделий фирмы Honer). Окказиональный экспрессивный интенсификатор honernie можно рассматривать и как пример графо-фонетической аллюзии к разговорно-просторечному наречию степени качества cholernie 'очень' $\leftarrow$ cholerny (переносн. 'такой, который раздражает'). 
Польский рекламный экспрессивный окказионализм najwarzywniejszy создан с нарушением лексико-грамматической сочетаемости морфем на базе относительного прилагательного при помощи префиксально-суффиксального форманта, используемого для образования форм превосходной степени качественных прилагательных. См.: «Warzywko». Najwarzywniejsze w kuchni (cp.: Najintensywniejszy aromat warzyw w kuchni).

Нарушением стилистической сочетаемости морфем сопровождается образование окказионального экспрессива pamięciocha (> pamięć), имеющего аугментативное значение, осложнённое субъективно-оценочным оттенком, передаваемым суффиксальным формантом -och $(a)$, который «переводит» неодериват в разговорную тональность: Simplus - Karciocha Pamięciochy.

Стилистическая разнородность деминутивного суффикса -ek и производящей основы - nomen abstracta głód, вопреки словообразовательной норме объединяемых в структуре рекламного экспрессивного неодеривата głodek, использована как средство создания прагматического эмоционально-экспрессивного эффекта. «Инфантилизация» абстрактного существительного głód привела к упрощению и конкретизации его значения, лишая это базовое nomen abstracta существенных признаков его десигната и тем самым способствуя изменению сознания и поведения потребителей, побуждаемых к деятельностной реакции - приобретению продуктов, с помощью которых можно легко справиться с маленьким неприятным существом, обозначенным как głodek: Serek Danio. Głodek sam w domu (https://danio.com.pl).

Как польские, так и русские рекламные окказионализмы достаточно часто образуются с нарушением стилистической сочетаемости морфем от основ иных категориальных лексико-грамматических свойств, чем требуется по условиям словообразовательного типа. Так, например, рекламные окказионализмы Empetrucha, stuchafon в рекламе тарифа Simplus (Empetrucha, stuchafony jak dzwony) созданы на базе асистемных производящих основ: в первом случае просторечный суффикс -uch(a) присоединяет к словоговой аббревиатуре Empetrzy (MP3), во втором случае суффиксоид-интернационализм -fon- добавлен к исконной глагольной основе stucha-, причем в слогане в качестве дополнительного средства эмоционального воздействия используется внутренняя рифма: stuchafony/dzwony.

Русский «рекламный» окказионализм похрустист образован также с нарушением лексико-грамматических условий сочетаемости морфем: суффикс -ucm добавлен к глагольной основе nохрусm-/nохрустеть (слоган: «Московский картофель». Похрустист? Иди на хруст»). Неодериват похрустист является структурным аналогом достаточно известного окказионализма пофигист 'тот, кому всё по фигу, т.е. безразлично', образованного на базе грубо-просторечного фразеологизма. Структурная аналогия, обусловленная тождественностью аффиксов (префикс по-, суффикс -ucm), порождает 
аллюзию, которая способствует наслоению смыслов: похрустист - тот же nофигист. Общее категориальное словообразовательное значение этих окказионализмов передается суффиксом -ист со значением «сторонник определенных идей и доктрин», присущим отсубстантивным nomina pertinentia.

Системно-логическая связь категорий «сторонник определенных идей и доктрин» « «название определенных идей и доктрин» способствовала созданию абстрактного существительного похрустизм на базе окказионализма похрустист. Неодериват похрустизм - название новой идеологии жизни, предлагаемой молодежи (ср.: пофигизм), - обязан своим появлением рекламной кампании, организованной производителями чипсов «Московский картофель»: Включи похрутизм!, Даешь похрутизм!, Твой похрустизм - крутая шттука!, Поддержи похрутизм!, Московский картофель. В похрустизме - сила!

Нарушение семантической сочетаемости морфем обусловило уникальное словообразовательное значение рекламного окказионализма, существительного pluralia tantum Мечталки - 'то, что способствует достижению состояния (названного глаголом мечтать)’. Узуальные существительные с суффиксом -лк- не имеют такого частного словообразовательного значения, поскольку этот суффикс сочетается с основами глаголов, называющих физические действия (ср.: веялка, молотилка, сеялка и др., см.: Русская грамматика. Словообразование имён существительных, §228). Значение семантически нерегулярного неодеривата, хрематонима Мечталки, обозначающего марку кукурузных хлопьев, раскрывается в парцеллированном слогане: Мечталки. Хрустящее лакомство для мечтателей! В экспрессивно-метафорическую перифрастическую часть слогана, указывающую на основные достоинства кукурузных хлопьев Мечталки, включено однокоренное слово мечтатели, называющее целевую группу потребителей и тем самым объясняющее, для достижения какого именно состояния служат Мечталки.

Появление в рекламном тексте окказиональных формально-семантических компрессатов может быть результатом одновременного осуществления двух словообразовательных операций - сращения и суффиксации. Пример тому - название новой торговой марки Чайкофский - результат аллюзивной графо-фонетической игры фамилией великого композитора (Чайковский), цель которой - увеличить продажу сахара с помощью эффектного названия. Внутренняя форма этого окказионального композита декодируется в рекламном зачине и слогане Любимый сахар чая и кофе! Чайкофский. Такое чистое наслаждение!

3. Рекламные окказионализмы-экспрессивы могут создаваться не в соответствии со словообразовательным типом, а на основании структурной аналогии, по образцу узуального слова, которое находится в том же рекламном тексте. Так, окказионализм хрустно, появившийся в рекламе нового сорта печения (Алле! О, «Причуда». Вкусно и хрустно ), образован от суще- 
ствительного хруст по аналогии с наречием вкусно путем одновременного присоединения суффиксов При создании качественного наречия на базе абстрактного существительного хруст игнорируются грамматические и формальные ограничения. Как и однокоренные неодериваты похрустист, похрустизм, окказионализм хрустно имеет метафорическое значение, поскольку называет уникальное потребительское свойство товара (печенья, чипсов), порождая синестетические вкусо-слуховые ассоциации, обусловливающие желание повторить действие - похрустеть, откусить с хрустом.

Аналогическому словопроизводству русских рекламных окказионализмов с помощью радиксоидов -мёт и -провод, продуктивных в узусе, сопутствует метафоризация, ср.: орехомет, пивомет, орехопровод, пивопровод. Обращает на себя внимание креативная механика образования в коротком рекламном тексте деривационной парадигмы, состоящей из метафорических окказиональных композитов, например: Орехомёт - орехов немерено! Орехопровод - орехов немерено! Ореходуй - орехов немерено! В рекламном зачине, посвященном шоколадному батончику «Сникерс», копирайтеры информируют о большом количестве орехов в его составе, используя компоненты -мет и -провод, а также -дуй.

Радиксоиды -мёт и -провод использовались ранее в рекламе пива (nuвомёт, пивопровод), компонент -дуй как часть композита появился впервые, и потому уникальный окказионализм ореходуй привлекает внимание молодежной целевой аудитории своей необычной императивностью (дуй - разговорн. 'поглощай в больших количествах'). Для расшифровки окказиональных компрессатов-композитов Орехопровод, Орехомет, Ореходуй используется визуальный код (образ шоколадного батончика), поскольку общий корень opex- не обеспечивает понимания этих метафорических композитов - контекстуально-стилистических синонимов имени собственного Сникерс.

Польские окказиональные прилагательные miastoodporny [= ycmoüчивылй к условиям жсизи в городе], pogodoodporny [= погодоустойчивый] созданы по аналогии с узуальным прилагательным wodoodporny 'водоустойчивый', ср.: Nissan Qshqai 2.0 I-way. Miastoodporny nomada; Actimel dla pogodoodpornych.

По аналогии с узуальным существительным ludożerca 'каннибал' путём замещения корневой морфемы lud- образованы экспрессивные окказионализмы cenożerca (RTV EURO AGD: «Potworny cenożerca»), lodożerca (Los sprzyja lodożercom, где lodożercy = пожиратели мороженого), также przygodożerca (Knorr, Nudle, przygodożercy, где przygodożercy = пожиратели приключений).

4. Рекламные экспрессивные неодериваты с уникальным словообразовательным значением образуются с помощью продуктивных в узусе аффиксов по окказиональным моделям (типам). Ср.: Сникерс $\rightarrow($ сникерснуть) $\rightarrow$ 
сникерсни, т.е. 'съешь Сникерс'(Не тормози. Сникерсни!); фрукт $\rightarrow$ (фруктануть) $\rightarrow$ фруктанем, т.е. 'выпьем напитки из фруктов' (Соки и нектары «Яблочкин». Фруктанем на всю катушку); Twix $\rightarrow$ (twixnać) $\rightarrow$ twixnijmy, т.e. 'съедим-ка Twix' (слоган в рекламе печенья Twix: Twixnijmy to razem!).

Продуктивные суффиксы -нy -, -nq- со значением «однократно совершить действие, названное мотивирующим глаголом», используются в узусе для образования глаголов совершенного вида от глаголов несовершенного вида (см., например: Русская грамматика. Глаголь, мотивированные глаголами, §836, §840). Экспрессивные окказиональные отсубстантивные глаголы сникерсни, фруктанем, twixnijmy, образованные с помощью суффиксов -нy $2^{-},-n q-$, имеют уникальное словообразовательное значение 'потребить то, что названо мотивирующим существительным'.

5. В процессе т.н. «авторского нейминга» российские рекламисты сознательно создают уникальные форманты, по звучанию напоминающие иноязычные морфемы и потому обладающие специфической экспрессией «заграничности». Пример тому - неодериваты с суффиксоидами -аль, -он, -угали(я), -эль: Моменталь (сухие экспресс-обеды, слоган: Перерыв на Моменталь. Прервись на момент); Чипсонь 'воздушные чипсы', ср. бульон, медальон, иансон; Чипсонь (Ешь «Чипсоньл», слушай панк-рок и будь что будет // www.advi.ru/page.php3?id=208); Спортугалия (сеть магазинов, продающих спортивные товары), Тортугалия (ЗАО «Челны-Хлеб», производящее торты и пирожные; слоган: Тортугалия. Страна Вечной Вкусноты, ср. с Португалия); Шармэль (пастила и зефир в шоколаде, слоган: Шармэль. Маленькая женская радость).

Окказионализмы-хрематонимы, созданные с помощью уникальных суффиксов, включаются в состав парцеллированных слоганов, где, как правило, есть экспрессивно-метафорическая перифраза, называющая достоинства рекламируемого продукта. С помощью такой перифразы легко декодируется семантика эстетически эффектного окказионализма-хрематонима Шармэль - ‘то, что придает женщине шарм': благодаря ассоциативным связям и парономазийной графо-фонетической перекличке возникает аллюзия: Шармэль $\rightarrow$ шарм + Шанель + Шарм эль Шейх, - которая базируется на стереотипе «успешной» современной женщины «с шармом», пахнущей духами «Шанель №5» и отдыхающей на дорогом курорте Шарм эль Шейх.

Русские асистемные окказиональные дериваты-компрессаты создаются рекламистами с помощью т.н. «телескопического словообразования» - особой разновидности контаминации, которая сопровождается неполным сохранением обеих исходных словесных единиц. В результате появляются формально-семантические компрессаты, состоящие из начальной части первого из слов, слагаемых в одно целое, и конечной части второго слова, ср., например: Согурт, Фругурт, фрутешествие. Семантика компрессатов«телескопидов» раскрывается с помощью внешего вербального контекста 
и/или визуального кода. Так, внутренняя форма окказионализмов-компрессатов Согурт, Фругурт раскрывается с помощью слова йогурт, включенного в рекламные тексты. Ср.: Наконеи-то у Растишки появилась новинка - СОГУРТ! Это напиток, который хорошо утоляет жажду, ведь в нем сок, фруктовое пюре и нежный йогурт! Создатели окказионализмов-«телескопидов» Согурт, Фругурт заменили начальный слог в слове йогурт элементами начальных слогов со- (сок) и $\phi p y$-(фруктовый), направляя внимание покупателей на достоинства новых марок молочных продуктов (не просто йогурт, а йогурт с добавлением сока, полный фруктов). Ср. с окказионализмом-компрессатом фрутешествие в кратком рекламном тексте Весёлое фрутешествие!, который не раскрывает значение окказионализма: оно дешифруется только с помощью визуального кода - рекламного плаката фирмы-производителя сока «Фруктовый сад» (фрутешествие - 'путешествие, которое можно выиграть благодаря потреблению сока «Фруктовый сад»').

Телескопические окказионализмы, продукты причудливой структурно-семантической контаминации морфемных элементов, не только позволяют увеличить объем информации, но и делают рекламный текст запоминающимся, динамичным, ярким и даже эвристическим, поскольку его реципиенты вынуждены решать нестандартную задачу, занимаясь дешифровкой «телескопида». Благодаря необычной форме и емкости содержания окказиональные компрессаты-композиты и «телескопиды»- являются эффективными средствами словесной образности. Экспрессивные рекламные компрессаты-композиты отражают различные ассоциативные связи между двумя предметами или явлениями, а само формирование образности и оценочности достигается чаще всего метафорическим переносом либо нарушением семантической сочетаемости морфем. При их образовании элиминируются те компоненты, которые могут быть либо восстановлены из невербальной части рекламного текста, либо подсказаны пресуппозицией.

Подводя итоги сопоставительного анализа, следует подчеркнуть, что и русские, и польские рекламные окказионализмы, рассмотренные в данной статье, можно разделить на две группы - системные и асистемные, или уникальные -, используя в качестве основного критерия степень креативности, определяющую статус окказионализма в рекламе.

К системным окказионализмам-компрессатам со слабо выраженной креативностью относятся неодериваты, образованные по продуктивным в узусе моделям. Они обладают значительно меньшей, чем уникальные окказионализмы, силой воздействия на реципиентов рекламных текстов.

Уникальные асистемные окказионализмы с ярко выраженной экспрессивностью обладают высокой степенью креативности. Асистемные окказионализмы целенаправленно вводятся в рекламный текст как экспрессивные знаки, ёмкие по своей семантике. Они эффективно воздействуют на информационное, интеллектуальное и эмоциональное состояние потребителей ре- 
кламы, провоцируя их на определенную реакцию в определенной ситуации. Введение в рекламный текст экспрессивных окказионализмов-компрессатов дает возможность свернуть лишние детали описания, сообщая структурную и эмоциональную напряженность высказыванию и при этом максимально насыщая его информацией.

Семантические границы уникальных, т.е. асистемных, окказионализмов, раздвигает аллюзивная игра, которую ведут их создатели, насыщая рекламные неодериваты оригинальными эмоционально-экспрессивными оттенками, что способствует метафоризации, являющейся эффективным средством семантической компрессии. Создание окказионализмов по уникальным моделям, с помощью уникальных формантов способствует успешному решению коммуникативных и прагматических задач, которые ставят перед собой рекламисты. Уникальные окказионализмы-экспрессивы - семантические компрессаты - оказывают сильное психологическое воздействие прежде всего на целевые группы потребителей детского и юношеского возраста, для которых характерны отсутствие критического мышления и высокая степень внушаемости.

Русские и польские рекламные окказионализмы, проанализированные в данной статье, практически не имеют шансов пройти все стадии конвенциональности и быть зафиксированными в словаре, однако они представляют собой интересный материал для сопоставительного лингвистического исследования в области креативных возможностей анализируемых языков, их словотворческого потенциала.

\section{Библиография}

Котлер Ф. (1996), Основы маркетинга, Москва.

Пашутин С. Б. (2007), Манипуляции и «зомбирование» в рекламе, «Лаборатория рекламы, маркетинга и PR», № 3 (52), http:// www.advlab.ru/articles/article600.htm.

Русская грамматика. Глаголь, мотивированные глаголами, Академия наук СССР, Институт русского языка, http://rusgram.narod.ru/836-849.html.

Русская грамматика. Словообразование имён существительных, Академия наук СССР, Институт русского языка, http://rusgram.narod.ru/208-255.html.

Benedikt A. (2004), Reklama jako proces komunikacji, Wrocław.

Spychalska M., Hołota M. (2009), Słownik sloganów reklamowych, Wydawnictwo Naukowe PWN, Warszawa.

\section{Источники языкового материала:}

URL российских интернет-баз:

http://www.content-stroy.ru/base_slogan.html,

http://www.sloganbase.ru/.

http://www.textart.ru/baza/slogan/list.html, http://www.top20brands.ru/, 


\section{OCCASIONALISMS IN ADVERTISING TEXTS: TO THE QUESTION OF COGNITIVE CODING (ON THE MATERIAL OF RUSSIAN AND POLISH LANGUAGES)}

(Summary)

The article gives an overview of the existing trends in creation of occasional words in advertising texts. Occasionalisms are very expressive because of unaccustomed perception and because of special concentration of content. The author reveals groups of Russian and Polish expressive advertising occasionalisms in regard to their content and structural features. The research of categories of advertising occasionalisms is of much importance in theoretical as well as in applied plans, that is in comparative and pragmatic ones.

Keywords: advertising texts, occasionalism, Russian and Polish expressive advertising neologisms

\section{ОККАЗИОНАЛИЗМЫ В РЕКЛАМНЫХ ТЕКСТАХ: К ВОПРОСУ О КОГНИТИВНОМ КОДИРОВАНИИ (НА МАТЕРИАЛЕ РУССКОГО И ПОЛЬСКОГО ЯЗЫКОВ)}

(Резюме)

В статье рассматриваются основные тенденции образования экспрессивных окказионализмов в рекламных текстах. Окказионализмы-экспрессивы способствуют эффективному когнитивному кодированию потребителей рекламы благодаря своей структурной нестандартности, а также наслоению смысловых оттенков. Автор статьи анализирует структуру, семантику и прагмастилистические свойства русских и польских окказионализмов-экспрессивов, поскольку их исследование имеет большое теоретическое и практическое значение.

Ключевые слова: тексты рекламы, окказионализмы, русские и польские рекламные экспрессивы 